\title{
Analisis Saluran Pemasaran Terintegrasi UMKM Badii Farm Purwakarta dalam Meningkatkan Volume Penjualan
}

\author{
Tika Annisa Lestari Koeswandi ${ }^{1}$, Ery Adam Primasakara ${ }^{2}$ \\ ${ }^{1}$ Prodi Kewirausahaan, Universitas Pendidikan Indonesia Kampus Tasikmalaya, Tasikmalaya, Indonesia \\ ${ }^{2}$ Sekolah PascaSarjana, Universitas Pendidikan Indonesia, Bandung, Indonesia \\ tikakoeswandi@upi.edu
}

\begin{abstract}
Having a role as the 'backbone' of the Indonesian economy, SMEs growth has decreased from year to year. One of them occurred at Badii Farm which experienced a decrease in sales volume due to the absence of an integrated marketing channel model. This study iaims to determine the integrated marketing channel system and the value network of Badii farm as an SME in increasing sales volume. This study is a qualitative descriptive study involving purposive sampling and using interview, observation and documentation instruments. The result shows that Badii Farm directly sells its products to customers so that there are no other alternative channels to distribute the products. Such a system runs almost in the majority of similar SMEs. Therefore, opening other marketing channels is necessary in order to increase sales volume and alternative markets. Some alternatives that can be used as other marketing channels is a wholesaler. Badii Farm is suggested to start breeding cattle for later distributed to other wholesalers so that the product is not glued to adult cattle and retailers where Badii Farm can have other market bags.
\end{abstract}

Keywords: integrated-marketing channel; sales volume; small-medium enterprise

\begin{abstract}
Abstrak
Memiliki peran sebagai 'tulang punggung' perekonomian Indonesia, pertumbuhan UMKM mengalami penurunan dari tahun ke tahun. Salah satunya terjadi pada UMKM Badii Farm yang mengalami penurunan volume penjualan karena tidak adanya model saluran pemasaran yang terintegrasi. Penelitian ini bertujuan untuk mengetahui sistem saluran pemasaran terintegrasi dan jaringan nilai UMKM Badii Farm dalam meningkatkan volume penjualan. Penelitian ini merupakan penelitian deskriptif kualitatif dengan melibatkan purposive sampling dan menggunakan instrument wawancara, observasi dan dokumentasi. Dari hasil penelitian mendapatkan Badii Farm langsung menjual produknya kepada pelanggan sehingga tidak ada alternatif saluran lainnya untuk mendistribusikan produk. Sistem seperti ini berjalan hampir di mayoritas UMKM sejenis. Oleh karena itu, pembukaan saluran saluran pemasaran lainnya dirasa perlu dalam rangka meningkatkan volume penjualan dan alternatif pasar. Beberapa alternatif yang bisa digunakan sebagai saluran pemasaran lainnya diantaranya bias berupa wholesaler. Badii Farm disarankan untuk mulai melakukan pembibitan ternak untuk kemudian disalurkan kepada wholesaler lainnya sehingga produk tidak terpaku kepada ternak dewasa saja dan Retailer, sehingga Badii Farm bisa memiliki kantung kantung pasar lainnya.
\end{abstract}

Kata Kunci: Saluran Pemasaran Terintegrasi; Volume Penjualan; UMKM

\section{PENDAHULUAN}

Usaha Mikro Kecil Menengah atau disingkat UMKM memiliki peran penting dalam pertumbuhan ekonomi di Indonesia. Peran tersebut diantaranya adalah mampu menyerap tenaga kerja, mengatasi masalah kemiskinan dan membantu pendistribusian hasil-hasil pembangunan (Sofyan Munawar et al., 2015) (Hamzah \& Agustien, 2019) (Utama, 2019). Di Indonesia, sektor bisnis seperti fashion $_{s}$ kuliner dan kerajinan menjadi yang paling diminati. Sedangkan UMKM dalam bidang jasa tidak banyak diminati dikarenakan tantangan untuk berinovasi memberikan pelayanan yang cepat dan efisien yang didukung dengan penggunaan teknologi (Bank Indonesia dan LPPI, 2015).

Peranya yang penting sebagai 'tulang punggung' perekonomian Indonesia tidak ditunjukan dengan pertumbuhan yang 
signifikan setiap tahun. Pertumbuhan UMKM di Indonesia terus menurun terutama dalam industri jasa. Dari tahun 1997 sampai tahun 2016, selisih angka penurunan jumlah UMKM mencapai 2,59\% (Badan Pusat Statistik, 2020). Penyebabnya kegagalan berkembangnya UMKM terletak pada fungsi saluran pemasaran yang tidak optimal (Yusri \& Sukardi, 2017).

Saluran pemasaran yang baik mencakup segala upaya pemenuhan kebutuhan produk/jasa mulai dari produsen, supplier, distributor hingga konsumen dengan menciptakan \& menawarkan nilai (Lukitaningsih, 2013) (Koeswandi et.al, 2018). Dari hulu ke hilir, saluran distribusi yang efektif dibangun dengan trust dan komitmen agar target perusahaan dapat tercapai (Suwatno \& Koeswandi, 2019). Pada sektor jasa, para anggota saluran pemasaran kurang mengetahui alur saluran sehingga pendistribusian selain tidak efektif tetapi proses penciptaan nilai pun tidak dapat dibangun (Utama, 2019).

UMKM yang mengalami masalah diatas salah satunya adalah Badii Farm. UMKM yang bergerak pada bidang jasa aqiqah inj mengalami penurunan penjualan pada 7 bulan terakhir. Salah satunya adalah dikarenakan tidak ada gambaran salur saluran pemasaran yang terintegrasi.

Sebuah penelitian perlu dilakukan untuk menggambarkan saluran menganalisis sistem saluran pemasaran terintegrasi dan jaringan nilai Badii Farm dalam meningkatkan volume penjualan. Output penelitian ini adalah model jalur saluran pemasaran terintegrasi pada UMKM. Hal ini dikarenakan, penelitian terdahulu tentang saluran pemasaran terpadu hanya berfokus pada analisis fakor dan marjin pemasaran (Jumiati et al., 2013) (Nurseto, 2018) (Putri et al., 2018).

Dalam pemasaran, seringkali penjual tidak langsung menjual barang dagangannya ke pengguna melainkan kepada beberapa perantara terlebih dahulu yang dikenal juga dengan sebutan saluran pemasaran, saluran perdagangan, atau saluran distribusi (Kotler
\& Keller, 2016). Palmatier et al (2014) menyatakan bahwa saluran saluran ini lah yang berfungsi sebagai gatekeeper atau penjaga gerbang antara produsen dan penggun terakhir. Krafft et al (2015) menambahkan bahwa saluran pemasaran merupakan salah satu elemen yang paling penting dalam rantai penyaluran nilai karena hampir seluruh hasil produksi akan melaluinya dan setiap perantara dalam saluran pemasaran (distributor, wholesaler, retailer) memiliki fungsi distribusi yang berbeda beda seperti transportasi, penyimpanan, penjualan, keuangan, serta pembangunan hubungan. Saluran saluran untuk mencapai segmentasi konsumen ini sering kali terdiri dari dua atau lebih saluran. Kotler dan Keller (2016) menyatakan bahwa saluran saluran tersebut disebut juga dengan multichannel marketing dimana perusahaan berada di tengah tengah jaringan nilai, sebuah sistem yang kerjasama yang dibuat perusahaan untuk mendapatkan, menambahkan dan menyampaikan nilai dari produk yang ditawarkan.

Saluran- saluran pemasaran memiliki peran yang sangat penting bagi perusahaan, karena banyak juga produsen yang tidak memiliki kemampuan finansial dan keahlian yang cukup untuk melakukan penjualan secara langsung yang cukup kepada konsumen (Kotler \& Keller, 2016).

Ada beberapa tingkatan dalam saluran saluran pemasaran dan para ahli pun memiliki pengistilahan yang berbeda namun tetap satu makna dalam menjabarkannya. Saluran pemasaran dimulai dari zero-level channel atau disebut juga direct marketing channel, dari produsen langsung ke konsumen kemudian setiap naik satu tingkatan maka akan bertambah satu perantara seperti retailer, wholesaler, dan jobber. Aturan yang sama pun berlaku untuk tingkatan saluran pemasaran business to business hanya berbeda pengistilahan saja.

Kotler dan Keller (2016) menyatakan bahwa ada 4 tahapan yang harus ditempuh oleh manajer dan pengusaha dalam menyusun 
sistem saluran pemasaran, yaitu Selecting channel member, Training and motivating channel members, Evaluating channel members, dan Modifying channel design and arrangements

Dalam tahapan evaluating channel member, manajer akan dihadapkan pada dua keputusan yang cukup penting yaitu dalam menentukan sistem channel power dan mendesain channel partnership. Dalam channel power, Kotler dan Keller (2016) menjelaskan bahwa ada 5 tipe pendekatan yang bisa dilakukan dalam rangka membangun kerjasama dengan tiap salurannya, yaitu Coercive power (produsen memberikan ancaman untuk memberhentikan supply), Reward power (produsen memberikan reward untuk performance yang baik), Legitimate power (produsen meminta perilaku tertentu dari saluran dan hal tersebut tertulis dalam kontrak), Expert power (produsen berusaha menguasai pengetahuan yang belum diketahui oleh saluran saluran pemasaran sebelumnya.), Referent power( produsen memiliki eksklusifitas tertentu sehingga saluran saluran pemasaran merasa bangga bisa menjadi bagian dari sistem.)

Armstrong et al (2017) menyatakan bahwa ada 2 sistem pemasaran yang bisa diterapkan dalam saluran pemasaran terintegrasi yaitu Sistem Pemasaran Vertikal: Sistem saluran distribusi yang terdiri dari producers, wholesalers, dan retailers yang berfungsi sebagai sistem terintegrasi. Ada rasa saling memiliki antar anggota saluran pemasaran. Sistem Pemasaran Horizontal: Sistem dimana dua atau lebih perusahaan beroperasi dalam level yang sama untuk berkolaborasi dalam mengikuti kesempatan pemasaran yang baru.

Armstrong et al (2017) juga menambahkan bahwa akan terdapat konflik yang terjadi dalam saluran pemasaran, dan konflik tersebut dikelompokan dalam 2 tipe yaitu Horizontal conflict, konflik yag terjadi diantara perusahaan perusaaan yang memiliki fungsi yang sama dalam satu level tertentu dan Vertical conflict, konflik yang terjadi antar anggota saluran dalam level yang berbeda.

Kotler dan Keller (2016) menjelaskan bahwa penyebab terjadinya konflik konflik ini adalah ketidak sesuaian tujuan antar saluran, ketidakjelasan peran dan hak masing masing anggota, perbedaan pendapat, ketergantungan perantara terhadap produsen.

Untuk mengatur dan memecahkan masalah yang terjadi dalam konflik, ada beberapa strategi yang bisa digunakan berdasarkan ajuan dari Kotler dan Keller (2016) yaitu Strategic justification (memberikan penjelasan strategis kepada setiap anggota bahwa segmen yang dilayani oleh segmen tertentu tidak terlalu menguntungkan secara penghasilan), Dual compensation (memberikan kompensasi kepada setiap saluran yang bisa membuka saluran baru), Superordinate goal ( menciptakan tujuan tujuan pemasaran baru), Employee exchange: pertukaran karyawan antar saluran), Joint membership: (keikutsertaan dalam asosiasi tertentu), Cooptation (menyertakan pimpinan saluran pemasaran dalam dewan penasehat perusahaan), Diplomacy, Mediation, and Arbitration dilakukan pada saat konflik yang terjadi cukup parah. Diplomacy artinya mengirim utusan untuk menyelesaikan masalah, mediation artinya meminta bantuan pihak ke tiga untuk mengkonsolidasi, sedangkan arbitration artinya menyerahkan keputusan kepada pihak lain yang akan memberikan keputusan, Legal resource( menyelesaikan lewat jalur hukum).

\section{METODE PENELITIAN}

Penelitian ini adalah jenis penelitian deskriptif kualitatif yang bertujuan untuk mengungkapkan kejadian atau fakta, keadaan, fenomena, variabel dan keadaan yang terjadi saat penelitian berlangsung dengan menyuguhkan apa yang sebenarnya terjadi. Metode penentuan sampel menggunakan non probability sampling, yaitu purposive sampling. Sampel yang diambil berdasarkan beberapa kriteria tertentu yang telah 
ditetapkan. Data yang dikumpulkan dalam penelitian ini terdiri dari data primer dan data sekunder. Data primer diperoleh melalui wawancara terarah (guided interview) dengan pimpinan UMKM Badii Farm beserta para peternak supplier Baadi Farm serta pengamatan langsung di lapangan dengan bentuk Observasi tidak terstruktur. Data sekunder diperoleh dari text book, laporan penjualan dan lain-lain. Hasil wawancara ditranskripsi dan kemudian dibuatkan ringkasan. Hasil observasi didapatkan dalam bentuk researcher's note. Laporan penjualan tiga tahun terakhir dan catatan dari pemilik dituliskan dalam bentuk uraian. Kemudian, data dan informasi yang telah dikumpulkan dianalisa secara deskriptif dengan textbook sebagai panduan analisis.

\section{HASIL DAN PEMBAHASAN}

Aliran Fisik

Tim pengadaan dari Badii Farm mengambil langsung domba dan sapi langsung dari para produsen di kandang kandang. Badii Farm langsung menyalurkan produk ternaknya kepada konsumen tanpa ada penyalur lainnya. Sehingga model saluran pemasaran yang didapat adalah:

Produsen -> Transport -> Badii farm -> Transport -> Konsumen.

Pada aliran fisik diketahui bahwa Badii Farm memiliki system pemasaran vertical yang sejalan dengan Armstrong et al (2017). Hal ini dikarenaka produsen dan Badii Farm merupakan entitas terpisah pada saluran yang terintegrasi.

\section{Aliran Hak Milik}

Hak kepemilikan akan produk dijalankan secara terstruktur dimana digambarkan dalam diagram yang memperlihatkan aliran hak milik dari pemasok ke pelanggan. Pada tingkat produsen, kepemilikan bahan-bahan produk menjadi tanggung jawab produsen di kandangnya masing masing. Jadi apabila ternak tidak sehat atau tidak mencapai berat yang diinginkan maka produsen bertanggung jawab hingga memasuki kriteria berat badan yang dibutuhkan yakni $15-25 \mathrm{~kg}$. Sedangkan pada tingkat produsen ke penyalur, hak milik menjadi tanggung jawab Badii Farm. Dimana Badii Farm memiliki tanggung jawab dan kriteria perusahaan untuk memelihara dan menggemukan ternak hingga mencapai kategori tertentu. Setelah itu, produk ternak sudah dapat dibeli oleh pelanggan. Hanya saja belum ada jaminan asuransi baik di tingkat produsen ataupun Badii Farm sehingga apabila ada kegagalan dalam penggemukan maka kerugian akan sangat terasa. Terutama karena Badii Farm menggantungkan pasokannya kepada produsen. Hal ini merupakan sebuah Legitimate power (produsen meminta perilaku tertentu dari saluran dan hal tersebut tertulis dalam kontrak) yang sejalan dengan pendapat Kotler dan Keller (2016). Sehingga model yang didapat adalah:

$$
\text { Produsen -> Badii Farm -> Konsumen }
$$

\section{Aliran Pembayaran}

Dana dan surplus yang diperoleh Badii Farm dan produsen sebenarnya bersumber dari berapa banyak pelanggan yang telah membeli produk ternak Badii Farm. Namun baik Badii Farm maupun produsen pada awalnya menggunakan fungsi pembiayaan sebagai contoh dapat dari perbankan yang menyediakan kredit modal kerja. Pembiayaan lainnya dapat dari modal tabungan pemilik usaha. Hal ini merupakan Referent power yang sejalan dengan dengan pendapat Kotler dan Keller (2016) dimana system ini disebut pemasaran vertical yang sejalan dengan Armstrong et al (2017). Model saluranya yaitu:

Produsen -> Bank -> BAdii Farm -> Bank -> Konsumen
Aliran Informasi
Informasi yang terjadi pada produsen ke bagian pengangkutan harus memberikan 
informasi banyaknya barang dan kualitas barang yang dikirim untuk Badii Farm sesuai dengan perjanjian. Pengangkut kemudian memberikan informasi tentang kebenaran data yang ditunjukan oleh Produsen. Sedangkan untuk Badii Farm kepada konsumen, konsumen mendapatkan informasi yang jelas mengenai kuantitas dan kualitas produk dan konsumen pun bisa mengecek langsung ke display di kandang untuk konfirmasi apabila masih ragu dengan produk ternak yang ditawarkan. Informasi dari Produsen kepada Badii Farm menjelaskan bahwa Badii Farm akan mendapat informasi tentang produk dan saran yang potential untuk dikembangkan ke kategori tertentu sesuai kebutuhan pasar. Kemudian, antara Badii Farm dengan konsumen, konsumen akan mendapatkan informasi tentang produk tersebut serta beberapa penjelasan dan hadist tentang keutamaan melaksanakan Aqiqah atau Qurban. Sehingga aliran pemasaranya sebagai berikut:

Produsen $->$ Transport-> Badii Farm-> Transport-> Konsumen

Pada aliran informasi diketahui bahwa Badii Farm memiliki system pemasaran vertical yang sejalan dengan Armstrong et al (2017). Hal ini dikarenaka produsen dan Badii Farm merupakan entitas terpisah pada saluran yang terintegrasi.

\section{Aliran Promosi}

Produsen memanfaatkan peran transporter untuk mempromosikan produk produknya. Setelah itu, Badii Farm mengambil best deal diantara para produsennya kemudian menyajikannya dalam bentuk infographic yang kemudian ditampilkan lewat beberapa social media. Jenis iklan yang digunakankan adalah baliho, brosur, pamlet, spanduk, iklan di media sosial. Sehingga aliran pemasaran terintegrasi adalah sebagai berikut:

Produsen -> Transport ->Badii Farm -> Sosial Media -> Konsumen.
Pada aliran promosi diketahui bahwa Badii Farm memiliki system pemasaran vertical yang sejalan dengan Armstrong et al (2017). Hal ini dikarenaka produsen dan Badii Farm merupakan entitas terpisah pada saluran yang terintegrasi.

\section{KESIMPULAN}

Badii Farm sebagai UMKM dalam bidang jasa pengelolaan domba aqiqah di Kabupaten Purwakarta berperan sebagai perantara bagi peternak peternak kecil di sekitar Purwakarta dan para pelanggan. Badii farm memiliki rancangan dan pengelolaan saluran pemasaran produk yang telah diatur secara efektif dan efisien. Badii farm berada di dalam sebuah saluran pemasaran dan berperan sebagai intermediary. Berdasarkan hasil analisa, Badii Farm langsung menjual produknya kepada pelanggan sehingga tidak ada alternatif saluran lainnya untuk mendistribusikan produk.

Adapun saran yang dapat diberikan pada penelitian ini Wholesaler, Badii Farm disarankan untuk mulai melakukan pembibitan ternak untuk kemudian disalurkan kepada wholesaler lainnya sehingga produk tidak terpaku kepada ternak dewasa saja. Peneliti selanjutnya disarankan untuk meneliti saluran pemasaran terintegrasi pada bidang non-jasa.

\section{DAFTAR PUSTAKA}

Badan Pusat Statistik. (2020). Tabel Perkembangan pada periode 1997 sampai 20013. https://www.bps.go.id/statictable/2014/0 1/30/1322/tabel-perkembangan-umkmpada-periode-1997--2013.html

Bank Indonesia dan LPPI. (2015). Profil Bisnis Usaha Mikro, Kecil dan Menengah (UMKM). Bank Indonesia Dan LPPI, 18-20.

BPS. (2018). Purwakarta Dalam Angka. Purwakarta: Badan Pusat Statistik Kabupaten Purwakarta.

Hamzah, lies M., \& Agustien, D. (2019). Pengaruh Perkembangan Usaha Mikro, 
Kecil, Dan Menengah Terhadap Pendapatan Nasional Pada Sektor Umkm Di Indonesia. Jurnal Ekonomi Pembangunan, 8(2), 215-228.

Hendriyani, Lis. (2020). \& Mileniall Disruption di https://mix.co.id/marcomm/7-millennialdisruption/ (diakses 29 januari 2019)

Jumiati, E., Darwanto, D. H., Hartono, S., \& Masyhuri. (2013). Analisis Saluran Pemasaran dan Marjin Pemasaran Kelapa Dalam Di Daerah Perbatasan Kalimantan Timur. Jurnal Agrifor, XII(1), 1-10.

Kartajaya, H. (2015). Indonesia WOW Markplus WOW We are WOW. Jakarta: Gramedia Pustaka Utama.

Koeswandi, T., Rahayu, A., \& Wibowo, L. A. (2017). Pengaruh Atmosfer Terhadap Costumer's Impression dan Dampaknya Pada Minat Beli Ulang. Jurnal Ilmu Manajemen Dan Bisnis, 8(2), 33. https://doi.org/10.17509/jimb.v8i2.1266 $\underline{4}$

Kotler, P., Kartajaya, H., Setiawan, I. (2010). Marketing 3.0: From products to customers to the human spirit . Hoboken: John Wiley \& Sons, Inc.

Kotler, P. (1997). Manajemen Pemasaran Analisis Perencanaan, Implementasi, dan Pengendalian (terjemahan Jaka Wasana). Jakarta: Salemba Empat.

Kotler, P., \& Keller, K. (2016). Marketing Management (Global Edition). Harlow: Pearson Education Limited.

Lukitaningsih, A. (2013). Perkembangan Konsep Pemasaran: Implementasi dan Implikasinya. Jurnal Maksipreneur: Manajemen, Koperasi, Dan Entrepreneurship, $3(1), \quad 21$. https://doi.org/10.30588/jmp.v3i1.85

Nurseto, S. (2018). Pengaruh Saluran Distribusi dan Promosi Terhadap Kinerja Pemasaran (Studi Kasus Pada UKM Furniture Kota Semarang). Jurnal Administrasi Bisnis, 7(2), 103. https://doi.org/10.14710/jab.v7i2.22695

Putri, R. K., Nurmalina, R., \& Burhanuddin, B. (2018). Analisis Efisiensi Dan Faktor
Yang Memengaruhi Pilihan Saluran Pemasaran. Mix: Jurnal Ilmiah Manajemen, $\quad 8(1)$, 109. https://doi.org/10.22441/mix.2018.v8i1. 007

Sofyan Munawar, S., Juningsih, E. R., \& Maulana, D. S. (2015). Proceeding Seminar Nasional Peningkatan Kapabilitas UMKM dalam Mewujudkan Umkm Naik Kelas Peran Komunikasi Pemasaran Dalam Sudut Pandang Umkm: Pembelajaran Untuk Pemberdayaan Umkm. 336-345.

Suwatno. (2017). Komunikasi Pemasaran Kontekstual. Bandung: PT. Remaja Rosdakarya

Suwatno \& Koeswandi, T. (2019). Contextual Marketing Communication. Bandung: Cendikia

Utama, I. D. (2019). Analisis Strategi Pemasaran Pada Usaha Mikro Kecil Dan Menengah (Umkm) Pada Era Digital Di Kota Bandung. Equilibrium, 7(January), $1-10$.

Yusri, M., \& Sukardi, D. (2017). Faktorfaktor penyebab kegagalan bisnis pada perusahaan mitra jaya abadi. Jurnal Manajemen Dan Start-Up Bisnis, 2(1), 124-131.

https://journal.uc.ac.id/index.php/perfor ma/article/view/445/398 